\title{
Continuidad y cambio en \\ las representaciones icónicas: significados simbólicos en el mundo \\ sur-andino
}

\author{
M. Ester Grebe
}

I

INTRODUCCIÓN

Toda concepción de mundo depende de una construcción simbólica de la realidad, la cual es percibida selectivamente por cada actor social en un contexto histórico y sociocultural específico. Dichas construcciones simbólicas se legitiman y validan al generarse consensos activados por los procesos de comunicación y transmisión cultural. Son entidades a la vez emisoras y receptoras de los procesos de permanencia y transformación, cuyos flujos y reflujos operan al interior de las matrices socioculturales. Accedemos a sus significados mediante el rescate y comprensión del discurso simbólico de los actores sociales, descubriendo los referentes émicos compartidos.

El presente estudio gravita en torno a los procesos de continuidad y cambio en el simbolismo sur-andino de Chile expresados en sus representaciones icónicas. Estas consisten en monumentos u objetos, decoraciones o dibujos - todos ellos documentos primarios elaborados por los actores sociales indígenas- capaces de proyectar mediante formas concretas algunos aspectos relevantes de la construcción simbólica del mundo sur-andino. En su calidad de fuentes originales, pueden aportar datos empíricos confiables para elaborar hipótesis explicativas de los procesos de estabilidad y cambio generados gradualmente en el eje diacrónico del encuentro de dos mundos: el indígena y el hispánico.

En los pueblos originarios del área sur-andina, los procesos de continuidad y cambio culturales y sociales parecen haber generado largas cadenas de 
transmisión. Mediante representaciones icónicas tanto del pasado precolombino y colonial como del presente etnográfico, se han preservado y comunicado patrones cognitivos y simbólicos que dan cuenta de ideas centrales y principios dominantes del mundo sur-andino. Entre dichas representaciones sobresalen algunos petroglifos prehispánicos, documentos etnohistóricos y decoraciones arquitectónicas coloniales, sumados a una gran cantidad de fotografías y dibujos etnográficos contemporáneos muchos de los cuales dan testimonios de aspectos generales o específicos de la construcción simbólica del mundo pan-andino. A partir de ellos, es posible intentar comprender los procesos complejos de continuidad y cambio mediante su discurso simbólico, confrontando sus similitudes y transformaciones. Para los efectos de la interpretación de sus referentes simbólicos, se ha considerado metodológicamente adecuado rescatar la decodificación ofrecida por algunas fuentes etnohistóricas coloniales y los abundantes testimonios de significados émicos que emanan de la iconografía etnográfica actual. No obstante, sus significados -que surgen con nitidez en las explicaciones de los dibujos y fotografías etnográficos actuales- pueden ser proyectados en un nivel meramente hipotético en el caso de las representaciones icónicas del pasado colonial y prehispánico.

En dicha iconografía se destacan los etnomodelos consistentes en diagramas o dibujos etnográficos, especies de mapas cognitivos émicos elaborados por los actores sociales. Dichos etnomodelos constituyen valiosos datos primarios de la experiencia sociocultural y operan como vehículos comunicativos eficientes en la transferencia de significados del discurso simbólico. Son capaces revelar procesos de continuidad y cambio, generando testimonios de estabilidad y persistencia o bien de variación y transformación. Cada uno de ellos da cuenta de una versión del mundo fenoménico compartido. Cada versión coexiste con diversas variantes cuyas transformaciones atestiguan la vitalidad del proceso de transmisión oral. Suelen representar tanto perspectivas cosmovisionales amplias como también detalles relevantes que inciden en la comprensión profunda de la trama simbólica. Encierran y pueden comunicar en forma directa o indirecta las claves de códigos compartidos.

En la interacción de componentes indígenas e hispánicos, es posible aislar al menos tres orientaciones: 1) la coexistencia o yuxtaposición de componentes culturales que fluyen a través de vías paralelas independientes manteniendo su individualidad; 2) la transformación abierta y continua de sus componentes que se ajustan adaptativamente a los cambios del entorno sociocultural y físico, y 3) la fusión o integración bicultural (o multicultural) que promueve la generación de mestizajes y sincretismos. No obstante, en estos procesos de generación, desarrollo, definición y consolidación de la cultura hispanoamericana se producen intersecciones complejísimas de estas orientaciones, en las cuales se conjugan la creatividad y el tradicionalismo, las adquisiciones, simplificaciones y pérdidas culturales, la originalidad y el formulismo, el incremento de la fuerza expresiva y su agotamiento. 
Los procesos de continuidad y cambio operan conjuntamente: son complementarios y recíprocos. La permanencia de un fenómeno a través del tiempo y del espacio implica un ajuste a las transformaciones que inevitablemente ocurren en el entorno social y cultural. Ello se da en dos planos principales: el morfológico y el semántico. Así, la preservación formal de una entidad simbólica puede ir acompañada de la transformación de sus referentes, o viceversa. $O$ bien, la preservación y transformación de formas y referentes simbólicos pueden operar conjuntamente a través del mismo proceso diacrónico. Generalmente, en las culturas tradicionales suele darse la coexistencia de formas fijas --que tienden a la permanencia de sus formas y/o referentes-; y de formas libres --que promueven el impulso dinámico y creativo en la tradición oral (Vansina, pp. 22-23).

La base empírica del presente trabajo consiste en materiales iconográficos pertenecientes a las culturas sur-andinas de Chile. Sobresalen en ellos los dibujos y fotografías etnográficas, algunos de los cuales ha sido posible complementar con explicaciones de los actores sociales acerca de sus significados. Mediante estos documentos visuales es posible rescatar émicamente su pensamiento y óptica cultural, sus reflexiones y asociaciones, su visión intracultural amplia y de detalles relevantes.

\section{II \\ REPRESENTACIONES ICÓNICAS: SIGNIFICADOS, PERMANENCIA Y CAMBIO}

Los referentes simbólicos de la iconografía sur-andina pueden ser comprendidos y relacionados con las ideas centrales y principios dominantes del mundo andino. Las ideas centrales se refieren al orden cósmico y la fertilidad; y los principios dominantes al dualismo, bifurcación del género, relaciones simétricas, reciprocidad y complementariedad. (Véase Lámina 1).

La idea central de orden cósmico revela la búsqueda de un equilibrio inmanente. Se externaliza en la concepción ordenada del cosmos, del conocimiento y creencias acerca de los astros, del tiempo astral y geocéntrico, del espacio y movimiento regulados por la geometría del cuadrado y del círculo, de los ciclos de la naturaleza y los números pares que denotan la búsqueda perseverante de la regularidad. Por su parte, la idea central de fertilidad revela la consecución y resguardo de la continuidad del mundo andino, su naturaleza, flora y fauna, y población humana. Se manifiesta en la permanencia de ciertas representaciones icónicas macro-andinas ampliamente difundidas - tales como la serpiente y el felino-; y de otras restringidas a un nivel microandino local - tal como el ícono carnavalesco aymara-hispánico denominado carnavalón - y por la importancia central de la pareja.

Los principios dominantes del dualismo, bifurcación de género y relaciones simétricas se expresan mediante el predominio de los números pares 


\section{PATRONES COGNITIVOS Y SIMBÓLICOS}

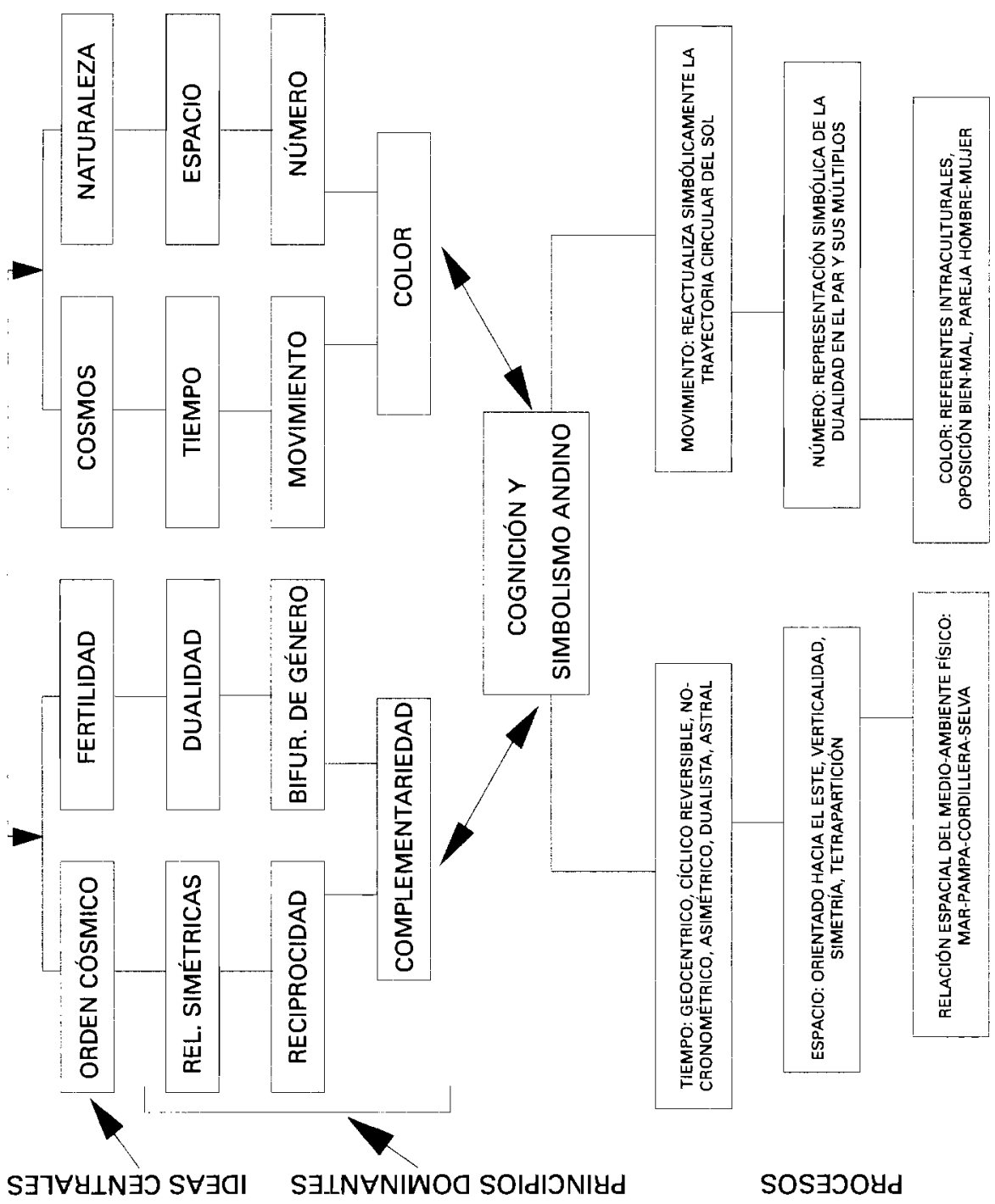

Lámina 1

Patrones cognicitivos y simbólicos sur-andinos: Ideas centrales y principios dominantes 
abarcando todos sus múltiplos, las estructuras duales de la bipartición y tetrapartición del espacio y movimiento, la simetría invertida de imágenes en espejo y de eventos simultáneos (Platt, pp. 1-56), y la importancia central de la pareja (Harris, pp. 21-40). Por último, la reciprocidad y complementariedad responden a normas tradicionales andinas reactualizadas mediante intercambios e interdependencias culturalmente pautadas en diversos dominios de la experiencia humana (Isbell 1978, pp. 11, 167-177).

En suma, las ideas centrales y principios dominantes del mundo andino y sus densas redes de relaciones se proyectan tanto en sus respectivos patrones cognitivos y simbólicos como en sus procesos y características. Ellos inciden en la construcción simbólica selectiva de la realidad sur-andina, que gravita tanto en la concepción circular de un tiempo geocéntrico cerrado y reversible, como también en la concepción del espacio que gravita hacia el Este, en una relación medioambiental regida por el eje vertical cordillera-mar. Asimismo, se relacionan con las concepciones y reactualizaciones simbólicas del movimiento, número y color. La totalidad de estas representaciones icónicas inciden, posiblemente, en largos ciclos de transmisión que definen la continuidad y transformaciones de formas y contenidos (Schaedel, pp. 117-128), generándose afinidades supralinguísticas que poseen, quizás, un fondo subliminal o inconsciente.

Examinaremos una serie de representaciones icónicas sur-andinas. La primera de ellas es un dibujo cosmológico colonial macroandino y su análisis correspondiente. Cada una de las láminas que siguen ilustran diversas facetas de los procesos sur-andinos de continuidad y cambio como también de sus significados simbólicos.

1. El dibujo cosmológico de Pachacuti Yamqui [ca. 1613]. ed. IFEA/CBC, Cusco, 1993; Zuidema y Urton, p. 109; Isbell 1976, pp. 37-56; 1978, p. 208; Urton, pp. 133, 203); Vallée, p. 115; Silverblatt, pp. 40-66. (Véase lámina 2, pg. 26).

2. Interpretación del dibujo de Pachacuti Yamqui [ca. 1613]. (Zuidema y Urton, pp. 62-69; Vallée, pp. 103-126). (Véase lámina 3, pg. 27).

Si adoptamos como punto de referencia inicial el dibujo cosmológico posthispánico colonial del siglo XvII producido por Pachacuti Yamqui [ca. 1613] -a partir de una representación cosmológica prehispánica ubicada en el templo de Coricancha, Cusco- constataremos la presencia de las antedichas ideas centrales y principios dominantes del mundo andino. (Véase Láminas 2 y 3 ). En dicho dibujo se representa el orden cósmico, fertilidad, dualidad, relaciones simétricas, bifurcación de género, reciprocidad y complementariedad. Se bifurca en dos series de entidades descendentes ubicadas a la derecha e izquierda de un eje cósmico central que las separa. En el sector superior de 
dicho eje central aparece Viracocha -imagen simbólica del creador incaico--, representado por una gran placa dorada ovalada sobre la cual están las cinco estrellas de Orión (de seis puntas c/u). Por debajo de Viracocha (eje cósmico central) aparecen las cuatro estrellas (de seis puntas también) de la cruz del sur. Por debajo de ésta, se sitúa la pareja humana. (Si se mira desde la Lámina hacia afuera, el hombre está a la derecha y mujer a la izquierda,

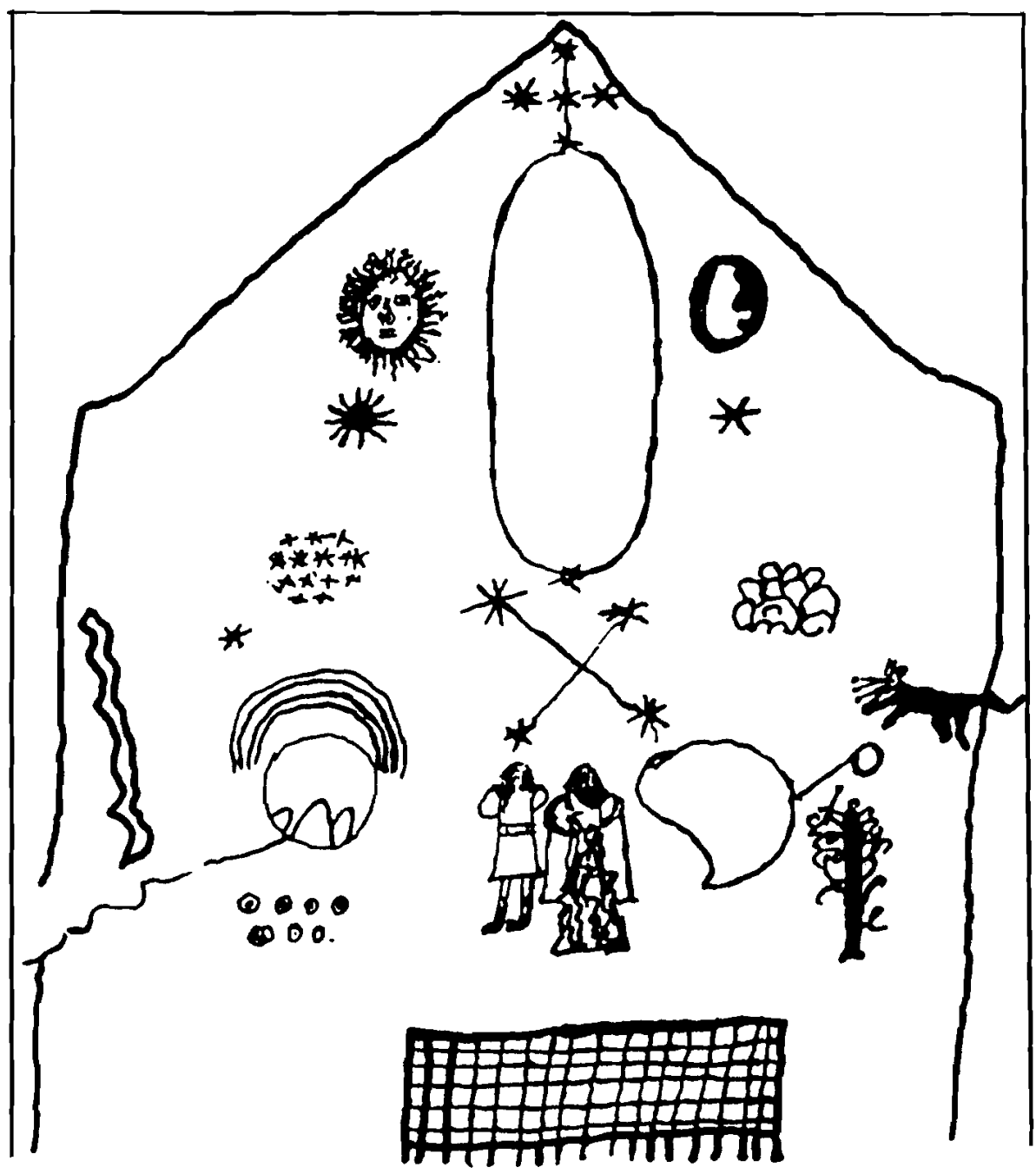

\section{Lámina 2}

El dibujo cosmológico de Pachacuti Yamqui [ca. 1613] 


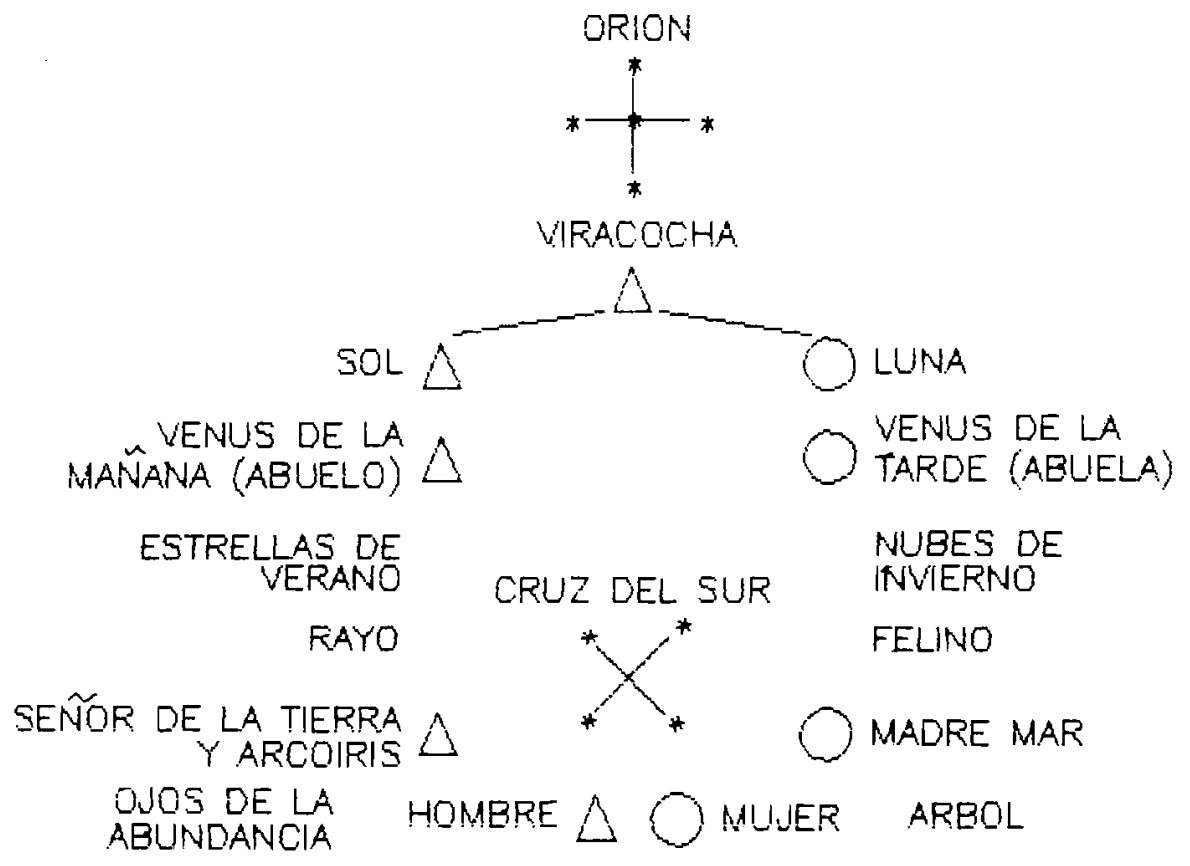

DEPOSITOS DE ALIMENTOS

Lámina 3

Componentes del dibujo cosmológico de Pachacuti Yamqui [ca. 1613]

cumpliéndose la norma andina). Más abajo se ubican las terrazas de las bodegas, que representan simbólicamente a la fertilidad agraria. A la derecha del eje central, se sitúan las entidades cósmicas asociadas al género masculino: sol, venus (lucero de la mañana o abuelo), estrellas de verano, rayo/o serpiente, señor de la tierra con arco iris, ojos de la abundancia. A la izquierda de este eje, se ubican las entidades cósmicas asociadas al género femenino: luna, venus (lucero de la tarde o abuela), nubes de invierno, felino, madre del mar alimentada por una vertiente, árbol joven.

Se aprecia en este dibujo la construcción simbólica del universo andino en dos perspectivas espaciales: vertical (alto-bajo), y horizontal (derecha-izquierda). El estrato vertical alto corresponde al dominio de los astros y deidades que ocupan un lugar primordial; y el estrato vertical bajo corresponde al dominio terrestre de los hombres acompañados de algunas entidades de mayor relevancia y poder (serpiente, arco iris, tierra, abundancia; y felino, nubes, mar, árbol). Mientras el dominio de los astros representa simbólicamente al orden cósmico, 
el dominio terrestre representa a la fertilidad. La división en dos series descendentes de entidades corresponde a la bifurcación de género. Es de interés señalar la presencia de la estrella, serpiente y felino, representaciones icónicas que parecen haber generado largas cadenas de transmisión en las culturas sur-andinas aymara y mapuche. (Véase Láminas 6, 7 y 8).

En la perspectiva horizontal, derecha e izquierda representan a la bifurcación de género en los dos estratos. Así, las representaciones y referentes masculinos y femeninos se distribuyen respectivamente a la derecha e izquierda. Además de Pachacuti, otras fuentes coloniales coinciden en ilustrar esta organización simbólica del espacio horizontal de la sociedad humana (Guamán Poma 1936; Garcilaso 1961, y otros). De ellas es posible inferir que el mundo andino ha sido construido metafóricamente mediante la demarcación de un paralelismo del género bifurcado en dos dominios interdependientes (Silverblatt, p. 20). Este constructo ha enmarcado la conceptualización del funcionamiento total del universo y de la sociedad humana, distinguiendo siempre los dos dominios genéricos del hombre y de la mujer que se proyectan en todo lo creado (ibid., pp. 20-39).

\section{Dibujo cosmológico de un pastor aymara (1977). (Véase Lámina 4).}

Este dibujo elaborado por un pastor de 25 años en Isluga representa dos de los tres estratos del cosmos aymara: araj-pacha (tierra alta de los astros) y manqha-pacha (submundo o tierra subterránea de los animales silvestres y espíritus del agua/música). [El dibujante excluyó taipi-pacha -tierra intermedia de los hombres - por haberla elaborado y entregado previamente]. En la tierra alta, reside la familia astral integrada por el padre sol [inti], la madre luna [pajse], los hijos estrellas [huara-huara] que incluyen los dos luceros y otras constelaciones, y la cruz (crucero], que corresponde a la cruz del sur, ubicándose en la tierra astral sobre la cabeza del cóndor (Grebe 1981, p. 62). Mientras el orden cósmico representa metafóricamente al mundo astral, la posición del sol y la luna (sol-hombre-arriba y luna-mujer-abajo) representa metonímicamente a la bifurcación de género y la dualidad referidos al status superior e inferior. El sincretismo indoamericano-cristiano denota una transformación polisémica de referentes simbólicos: el sol es también el Santísimo Sacramento que restituye la salud; y la luna por ser mujer y madre es al mismo tiempo Virgen María y pachamama (Grebe 1980, p. 144; 1981, p. 63).

En el submundo, residen los animales silvestres incluyendo ocho animales sagrados que acompañan a seren'-mallku y seren'-t'alla, los espíritus del agua subterránea y de la música (Grebe 1989-90, pp. 35-40). Dichos animales son: cóndor, águila, quirquincho, felino, pájaro-chullumpe, serpiente, lagarto y sapo. Es este el mundo indómito de las fuerzas naturales donde confluye lo primigenio y lo incontrolable, la fertilidad y el nacimiento de la vida. 


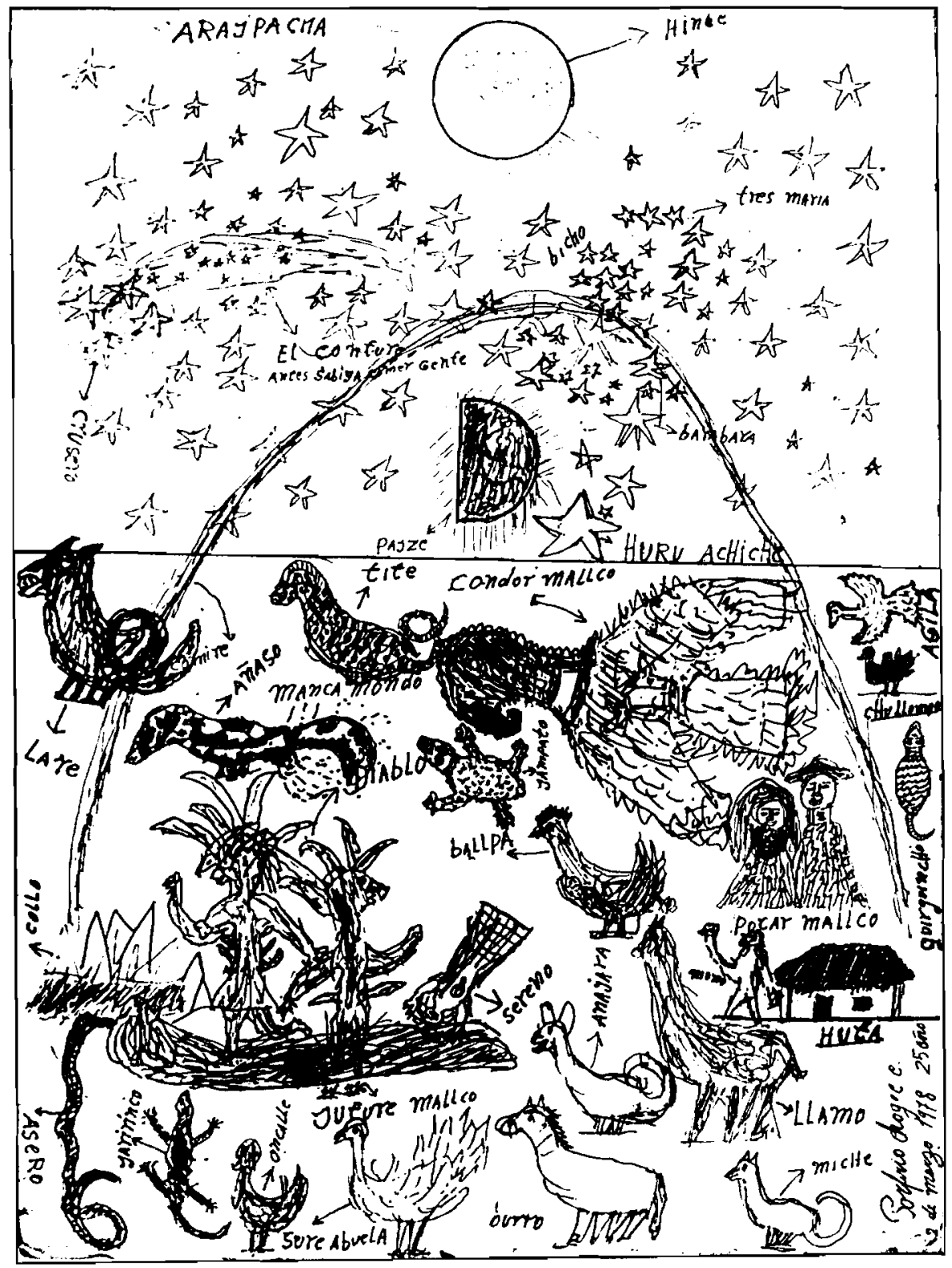

Lámina 4

Dibujo cosmológico de un pastor aymara [Isluga 1977] 
4. Etnomodelo de la concepción del tiempo de dos campesinos mapuches (1992). (Véase Lámina 5).

Este etnomodelo mapuche representa una concepción del tiempo geocéntrica, cíclica y reversible, no-cronométrica, asimétrica, dualista y astral, que se orienta según la dirección del movimiento solar. Sus principales indicadores de tiempo diurno y nocturno derivan respectivamente del sol y venus -planeta percibido como dos luceros: el de la tarde y del alba-. Asimismo, se establecen relaciones con otros astros (luna), planetas y constelaciones (cruz del sur, vía láctea, etc.). Esta concepción del tiempo, típicamente sur-andina, es una metáfora del orden cósmico reactualizado en el mundo astral (Grebe 1990, 1992).

5. Permanencia y transformaciones de la estrella. (Véase Lámina 6, página 147)

En el mundo astral sur-andino, las estrellas representan a los hijos del sol y de la luna, integrando junto a ellos la gran familia astral. La estrella principal es venus, percibida como dos luceros: el de la tarde y el del alba. Sus movimien-

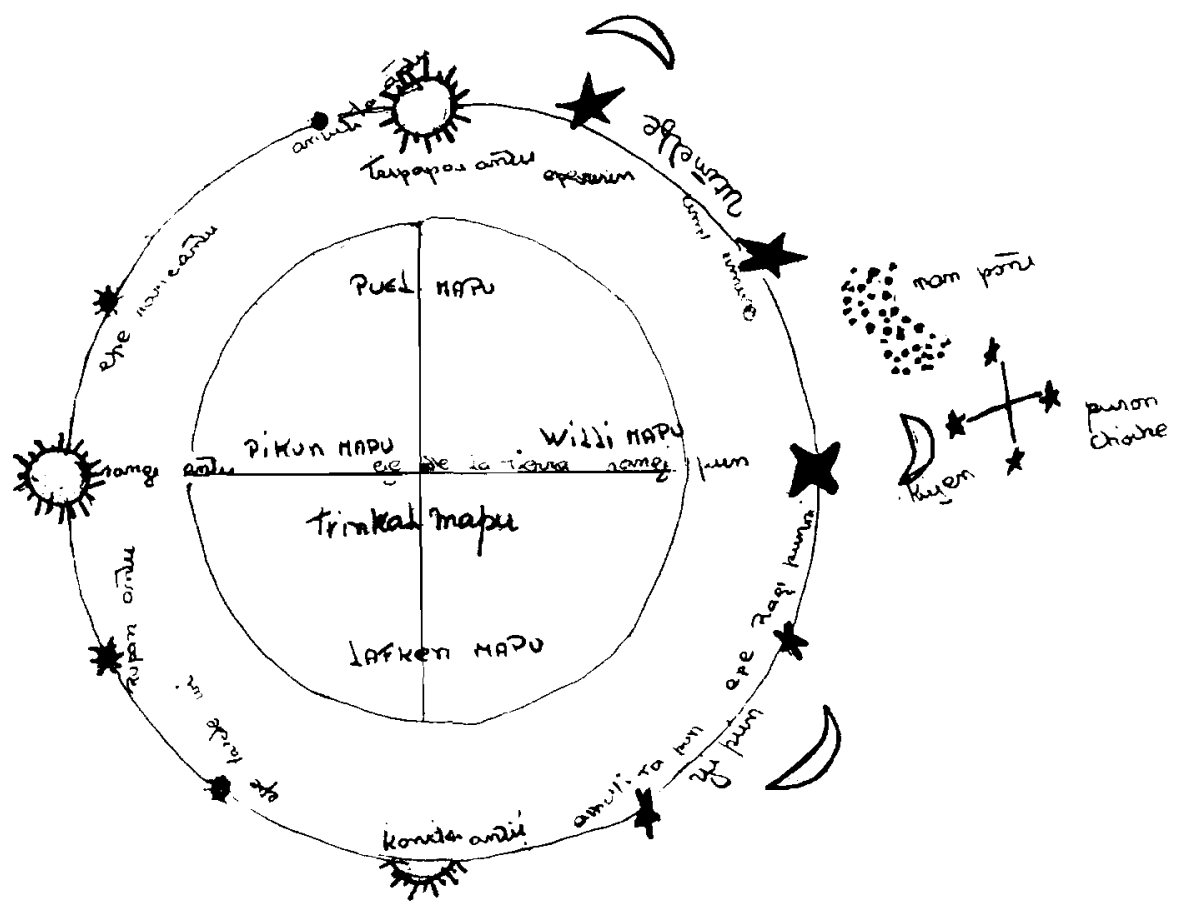

Lámina 5

Etnomodelo de concepción del tiempo de dos campesinos mapuches [Trumpulo 1992] 


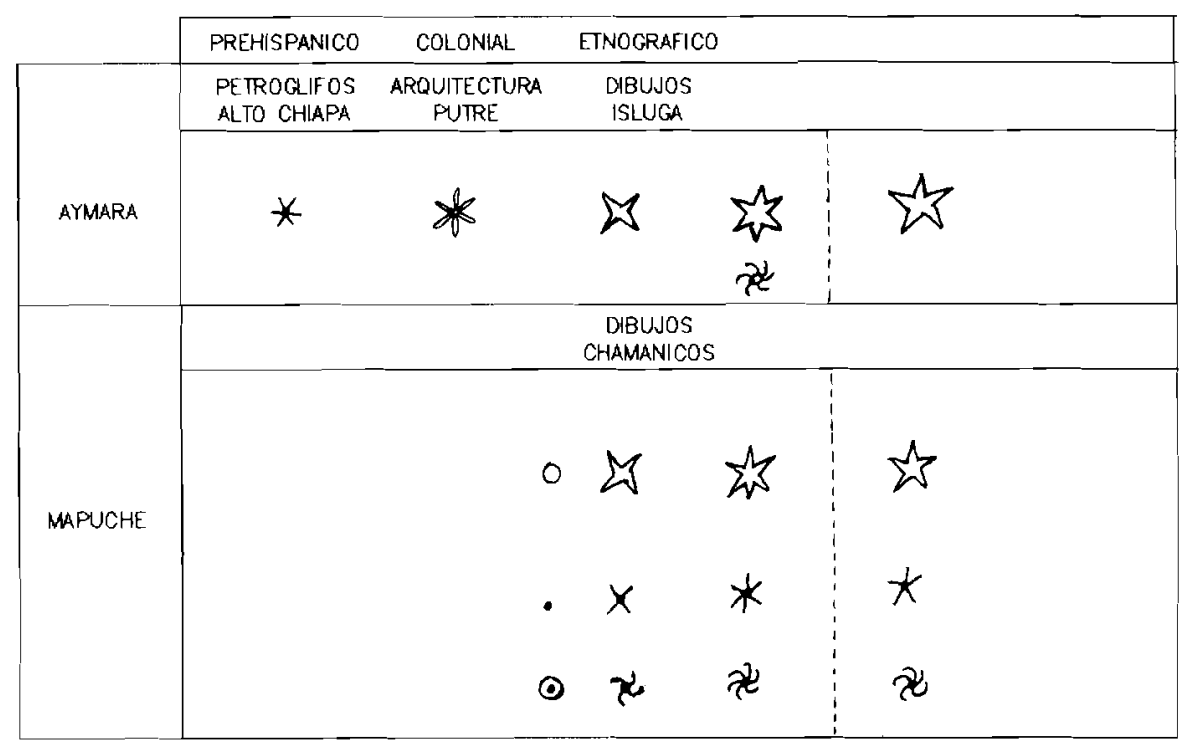

Lámina 6

Permanencia y tranformaciones de la estrella

tos y posiciones específicas guían el reconocimiento del tiempo nocturno. Antiguamente, se rendía culto a ciertas estrellas que eran más visibles durante la noche y se hacían pronósticos y vaticinios observando sus características (Zuidema y Urton, pp. 95-97).

En el mundo andino, la estrella ha conservado su importancia como indicador del tiempo nocturno. Esto explicaría su persistencia en la iconografía prehispánica, colonial y etnográfica. No obstante, su morfología presenta numerosas transformaciones. En los petroglifos de Chiapa, la estrella aymara de seis puntas es idéntica a aquellas representadas en el dibujo colonial de Pachacuti (Lám. 2). En la arquitectura colonial de Putre, reaparece la misma estrella cuyas seis puntas parecen pétalos finos de una flor. En los dibujos etnográficos aymaras, aparece una estrella de cuatro o seis puntas agudas; o bien, como círculo pequeño con seis rayos semicirculares. Por su parte, en los dibujos chamánicos mapuches aparece la estrella en una variada gama de transformaciones formales: como simple punto, pequeño círculo vacío, pequeño círculo con un punto en su interior, estrella de cuatro o seis puntas agudas con o sin punto en su interior, punto central con cuatro o seis rayos finos, $y$ pequeño círculo con seis rayos semicirculares.

En ambas culturas aymara y mapuche, la estrella de cinco puntas - que no corresponde a la simbología numérica andina que privilegia los paresderiva muy posiblemente de la estrella de la bandera chilena. De hecho 
aparece en la actualidad tanto en las banderas mapuches chamánicas y del ngillatuí como en la platería artesanal aymara. En suma, la estrella permanece como símbolo relevante experimentando una metamorfosis formal flexible. A juzgar por las analogías entre los significados de las estrellas de Pachacuti (Lám. 2) y las aymaras y mapuches contemporáneas, parecería ser que sus referentes se hubiesen preservado.

\section{Permanencia y transformaciones de la serpiente. (Véase Lámina 7).}

En la iconografía aymara, la serpiente es una representación metafórica de la fertilidad (Grebe 1989-90). Reaparece en petroglifos, en decoraciones de iglesias coloniales y, muy frecuentemente, en dibujos cosmológicos y parafernalia ritual altiplánica. Se encuentra, en los petroglifos de Alto Chiapa y en los relieves de fachada en la Iglesia colonial de Belén (precordillera, I Región de Chile); en la culebrilla de lanas multicolores que llevan las niñas solteras en su mano derecha, los hombres en su espalda, y ciertos camélidos más fértiles en sus orejas (altiplano, I Región de Chile). Aparece su forma ondulante vertical en varios dibujos cosmológicos: tanto en Pachacuti (Lám. 2, rayo-serpiente) como en numerosos dibujos etnográficos actuales (Lám. 4). En todos dichos casos es un símbolo prehispánico asociado a la fertilidad, cuyos referentes positivos discrepan con los referentes occidentales cristianos.

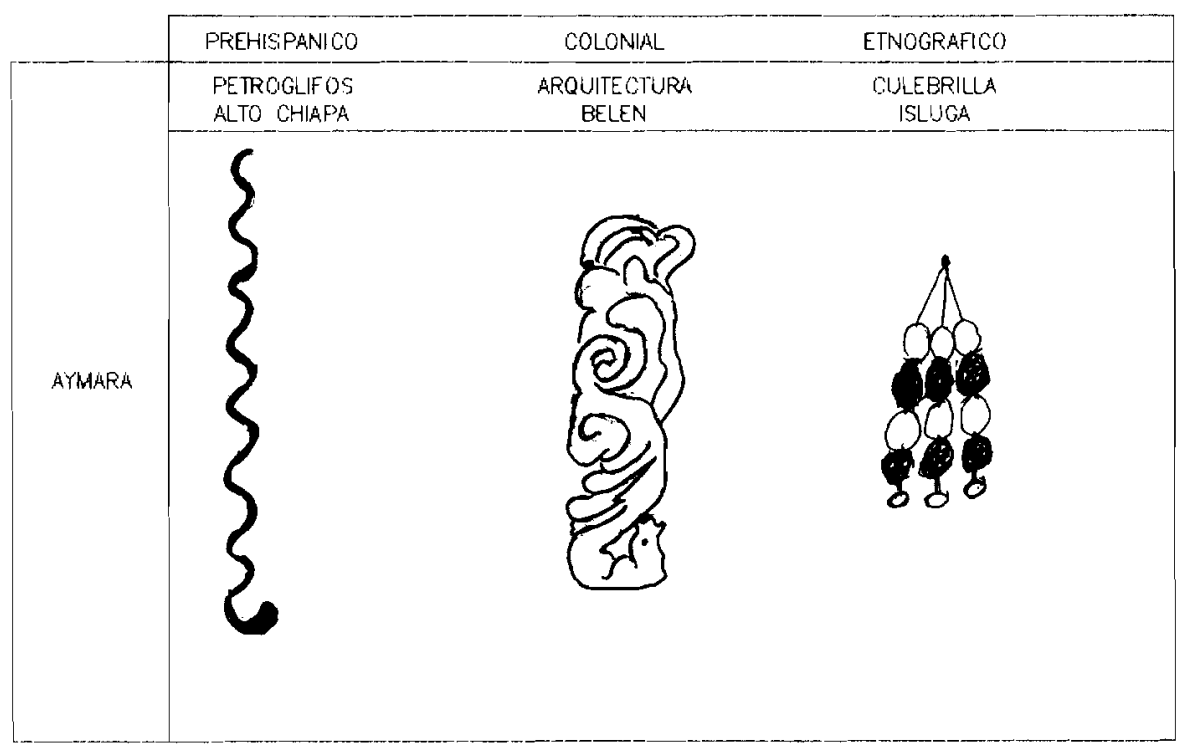

Lámina 7

Permanencia y tranformaciones de la serpiente 
7. Permanencia del felino. (Tschopik, p. 276; Grebe 1989-90, pp. 41-44). (Véase Lámina 8, página 150).

Si se comparan dos representaciones de las mesas (altares indoamericanos andinos) que poseen una pareja de felinos asociados al rito de enfloramiento del ganado, se observa la extraordinaria similitud de la primera (Chucuito, 1951) con la segunda (Isluga, 1989-90). Después de casi cuarenta años, se repite tanto la disposición espacial dualista y simétrica en la bipartición de los objetos de culto representados sobre la mesa, como también la bifurcación de género de la pareja de felinos macho y hembra. Tanto en el pasado (1951) como en el presente (1989-90), tanto en el altiplano peruano de Puno (Chucuito) como en el altiplano chileno de la I Región (Isluga), se ha reproducido un contenido esencial del simbolismo andino que gravita específicamente en la idea central de fertilidad. Se cree que el felino es el pastor sobrenatural de los mallkus (espíritus de la montaña), poseedores de todo el "ganado" silvestre. Por tanto, se rinde culto a este "animal-pastor" en el rito de enfloramiento dedicado a los mallkus para lograr el bienestar general y multiplicación del ganado, favoreciendo en consecuencia a su pastor y dueño.

\section{Permanencia y transformaciones de la cruz. (Véase Lámina 9), (página 35).}

La cruz andina indoamericana es parte del mundo astral. Aparece representada en documentos coloniales (Pachacuti, Lám. 2) y en dibujos etnográfi$\cos$ en sus formas vertical e inclinada. En las culturas aymara y mapuche, la cruz indoamericana es cuadrada y polisémica. Sus referentes astrales comunes principales son la cruz del sur y las tres Marías o cinturón de Orión; y su referente terrestre es la tetrapartición de la tierra, ya sea en cuatro ayllus (aymaras) o en cuatro lugares de la tierra (mapuches) en los cuales residen cuatro familias de mapuches del este, sur, oeste y norte (pewenches, williches, lafkenches y pikunches). Otro referente mapuche de la cruz es la demarcación espacial de las cuatro familias de dioses de los cuatro puntos cardinales que resguardan las cuatro esquinas de la tierra (Grebe 1972, pp. 52-56; 1973, pp. 24-28).

Las formas vertical o inclinada de la cruz indoamericana representan a variaciones nocturnas visibles en las posiciones de la cruz del sur. Por su parte, la cruz cristiana se introduce a partir del descubrimiento de América, junto a la iniciación del proceso de evangelización del área andina. La mayor extensión del brazo vertical de la cruz latina es su principal diferencia morfológica con la cruz cuadrada indoamericana de brazos equidistantes.

Es de interés señalar que las tres formas descritas de la cruz (Lám. 9) poseen correspondencias morfológicas transculturales con tipos de cruces conocidas, correspondientes a: 1) la cruz griega (crux quadrata), 2) la cruz de San Andrés (crux decussata), y 3) la cruz latina (crux immissa). Todas ellas se utilizan en las religiones cristianas como símbolo de la crucifixión de Cristo. 


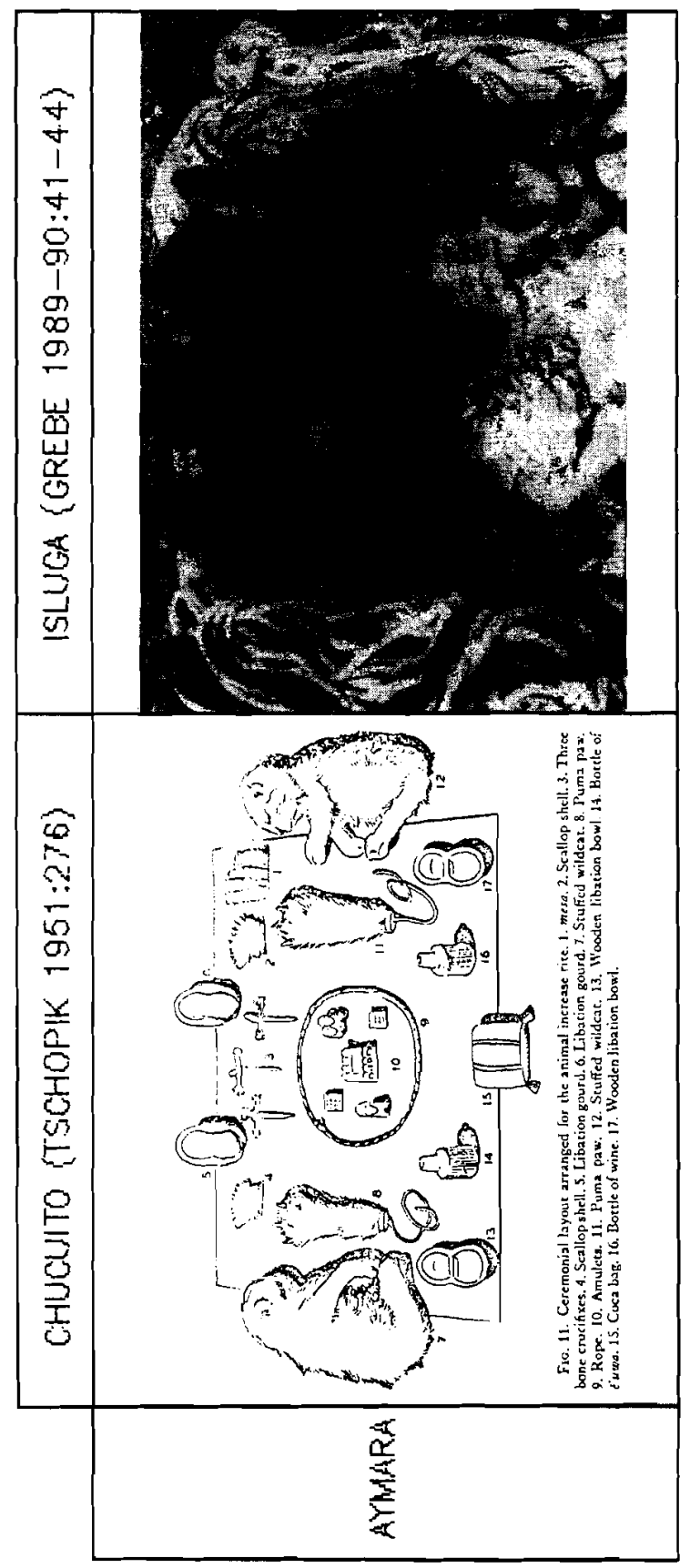

Lámina 8

Permanencia del felino 


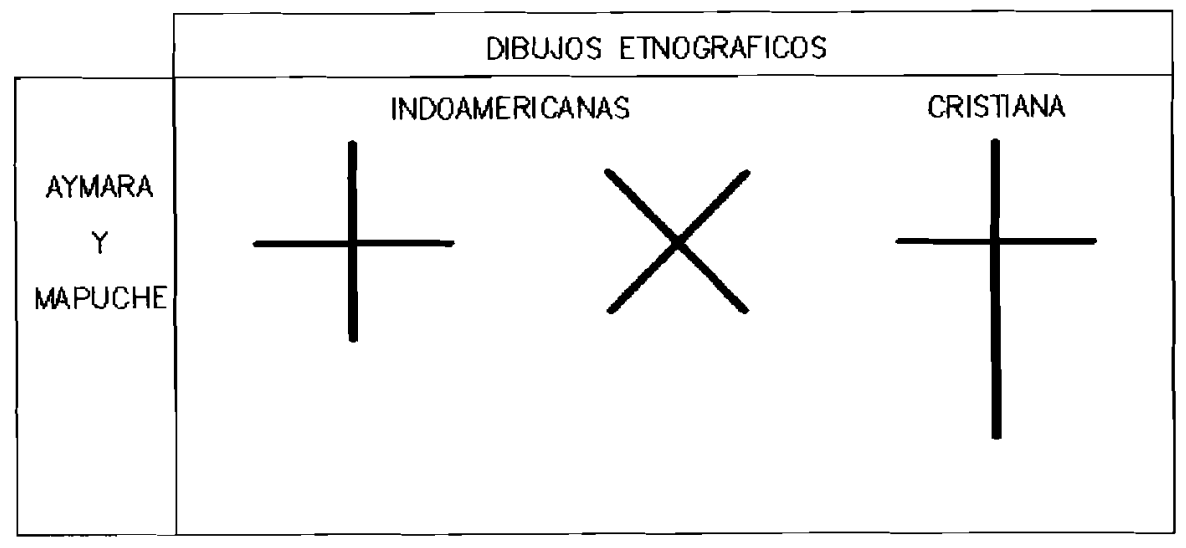

Lámina 9

Permanencia y transformaciones de la cruz (crucero)

Dada su similitud y compatibilidad formal con las cruces indoamericanas, la cruz cristiana es probablemente uno de los símbolos que ha tenido más aceptación en las culturas andinas (Casaverde, pp. 193-195). Las implicancias de este hecho merecerían un estudio más profundo y una discusión amplia, que no es posible incluir en el presente trabajo.

\section{III}

\section{RESUMEN Y PERSPECTIVAS}

Este trabajo incursiona preliminarmente en el complejo tema del simbolismo sur-andino en la perspectiva de su continuidad y cambio. Por tanto, sus resultados están sujetos a las modificaciones sugeridas por nuevos hallazgos incorporados en una investigación de mayor profundidad.

A partir de los criterios, categorías y óptica general de los actores sociales, se ha desarrollado la comprensión émica de una serie de representaciones icónicas sur-andinas. Reforzadas con una base suficiente de datos etnográficos y bibliográficos, estas representaciones icónicas permiten comprender cabalmente el discurso simbólico sur-andino. En dicho discurso, se expresan las ideas centrales de orden cósmico y de fertilidad, como también los principios dominantes de la macrocultura andina. Estos últimos se reactualizan en la dualidad, relaciones simétricas, bifurcación de género, reciprocidad y complementariedad que modelan los constructos ideacionales como también sus reactualizaciones rituales. Por una parte, la concepción central del orden cósmico se reactualiza en la cosmología. Esta última a su vez valida y legitima las concepciones cíclicas de tiempo, espacio y movimiento, como también la permanencia y transformaciones de la estrella. Por otra parte, tanto la idea 
central de fertilidad como los principios dominantes de la dualidad, bifurcación de género y complementariedad se relacionan con la permanencia de la pareja vinculada a la vida, supervivencia de la especie y continuidad cultural. La permanencia y transfomaciones de la serpiente y del felino están vinculadas al submundo indómito incontrolable de las fuerzas naturales del mundo silvestre. Por el contrario, la permanencia y transformaciones de la cruz proporcionan evidencias de sus afinidades morfológicas.

A partir de la Conquista, la interacción entre las culturas indígenas e hispánicas produce una confrontación de cosmovisiones, patrones cognitivos, símbolos y referentes. En dicha confrontación, se van precisando sus contradicciones y afinidades, produciéndose entre ambas culturas diversos matices intermedios o alternativos. Parece posible asumir que mientras más acentuados han sido los contrastes que bloquean el desarrollo del sincretismo entre ambas culturas, más perdurable ha sido la coexistencia de patrones de continuidad antagónicos. Y que, en cambio, cuando las afinidades entre los símbolos y/o sus referentes de ambas culturas han demostrado ser mayores, se han generado con mayor agilidad las condiciones para la maduración espontánea del sincretismo y de la integración cultural.

Esta proposición explicativa permite comprender el fenómeno de la perdurabilidad del dualismo y del simbolismo numérico del par o pareja en las culturas andinas, los cuales presentan un contraste esencial con el simbolismo del tres asociado con la Santísima Trinidad en el contexto de la religión católica. Mientras en la cultura hispánica cristiana el número tres se asocia a la divinidad y su perfección, en las culturas indígenas andinas este referente se asocia al par y sus múltiplos, al orden y equilibrio cósmicos. De este modo, se produce una contradicción básica entre simbolismo numérico cristiano e indígena. Mientras el tres representa simbólicamente al bien en el cristianismo, se asocia al mal y a las energías negativas en las culturas andinas. Esta contradicción se advierte también en los referentes positivos de fertilidad asignados a la serpiente, que han logrado persistir hasta hoy en la simbología sur-andina. Contrariamente, en el cristianismo dicha serpiente es una metáfora del mal. Algo similar ocurre con el felino andino. Pareciera ser que estos referentes contradictorios han sido capaces de resistir o aminorar la aculturación y el sincretismo religioso desarrollado en el transcurso del período colonial junto al proceso de evangelización del área sur-andina.

A pesar de las divergencias en sus respectivos referentes, las cruces cuadradas indoamericanas y la cristiana latina han demostrado poseer una convergencia generada por su coincidencia morfológica. En verdad, la cruz ha sido uno de los símbolos cristianos de mayor aceptación en las culturas andinas, siendo objeto de respeto y veneración (Casaverde, pp. 193-195). Dicha veneración no está dirigida al objeto material sino al espíritu que habita la cruz (Núñez del Prado, p. 102). A las cruces pequeñas mantenidas en el hogar - generalmente en su puerta principal - se les atribuyen propiedades $o$ 
"poderes" profilácticos, considerándose efectivos sus poderes para ahuyentar males y mala suerte del hogar. Un caso específico es la cruz de palqui en Chile, de origen mapuche. El fuerte arraigo de estas cruces en ésta y otras sociedades indígenas sur-andinas evoca el rol integrativo y sincrético que ellas parecen desempeñar y podrían seguir desempeñando.

La cruz cristiana se diferencia morfológicamente de las cruces indígenas solo en el mayor tamaño de su brazo vertical. Debido a su forma unitaria y poderes asignados, puede contribuir, eventualmente, a la superación de las contradicciones entre los universos simbólicos indígenas y de la sociedad mayor. Puede, asimismo, promover una mayor comprensión recíproca y fraterna que incida en una búsqueda respetuosa y encuentro de identidades culturales, y en una superación de las contradicciones del etnocentrismo y del prejuicio.

\section{BiBLIOGRAFÍA}

Casaverde, Juvenal. "E] Mundo Sobrenatural en una Comunidad". Allpanchis. Cusco, Perú). 1970, 2, pp. 121-244.

Garcilaso de la Vega, "el Inca". The Incas: The Royal Commentaries of the Inca Garcilaso de la Vega [1609], Alain Gheerbrant ed.. Nueva York. Avon Books, 1961.

Grebe, M. Ester, et al. "Cosmovisión Mapuche". Cuadernos de la Realidad Nacional, 1972, 14. pp. 46-73.

Grebe, M. Ester. "El Kultrún Mapuche: Un Microcosmo Simbólico". Revista Musical Chilena 1973, XXVII, 123-124, pp. 3-42.

Grebe, M. Ester. Generative Models, Symbolic Structures and Acculuration in the Panpipe Music of the Aymara of Tarapacá, Chile. Belfast, The Queen's University of Belfast, Ph.D. Thesis (Social Anthropology). 1980. 2 vols.

Grebe, M. Ester. "Cosmovisión Aymara". Revista de Santiago (Museo Nac. Vicuña Mackenna). 1981, 1, pp. 61-79.

Grebe, M. Ester. "El Culto a los Animales Sagrados Enblemáticos en la Cultura Aymara de Chile". Revista Chilena de Antropología (Univ. de Chile), 1989-1990, 8, pp. 35-51.

Grebe, M. Ester, "Etnomodelos: Una Propuesta Metodológica para la Comprensión Etnográfica". Revista de Sociología. (Univ. de Chile), 1990, 5, pp. 105-114.

Grebe, M. Ester. "Concepción del Tiempo en las Culturas Indígenas Sur-Andinas". En Time and Astronomy at the Meeting of Th'o Worlds, CESLA, Universidad de Varsovia, 1994, pp. 297-313.

Guamán Poma de Ayala, Felipe. El Primer Nueva Crónica y Buen Gobierno [ca. 1613]. Paris, Institut d'Ethnologie, 1936.

Harris, Olivia. "Complementarity and Conflict: An Andean View of Women and Men". En J.S. La Fontaine ed., Sex und Age as Principles of Social Differentiation, Londres, Academic Press, 1978, pp. $21-40$.

Isbell, Billie Jean. "La Otra Mitad Esencial: Un Estudio de Complementariedad Sexual Andina". Estudios Andinos, 1976, 5, pp. 37-56.

Isbell, Billie Jean. To Defend Ourselves: Eiology and Ritual in an Andean Village. Austin, Institute of Latin American Studies, The University of Texas, 1978. 
Núñez del Prado, Juan. "El Mundo Sobrenatural de los Quechuas del Sur del Perú a través de la Comunidad de Qotobamba". Allpanchis (Cuzco, Perú), 1970, 2, pp. 57-119.

Pachacuti Yamqui, Joan de Santa Cruz. "Relación de Antigüedades deste Reyno del Piru" [ca. 1613]. (Edición facsimilar con estudio etnohistórico y lingüístico de P. Duviols y C. Itier), Institut Français d'Etudes Andins/CBC, Cusco (Perú), 1993.

Schaedel, Richard. "2.000 Años de la Continuidad Cultural de los Muchik en la Costa Norte del Perú”. Ibero-Amerikanisches Archiv, N.F., 1987, 13, 1. pp. 117-128.

Silverblatt, Irene. Moon, Sun, and Witches: Gender Ideologies and Class in Inca and Colonial Perú. Princeton (N.J.), Princeton University Press, 1987.

Platt, Tristán. Espejos y Maiz: Temas de la Estructura Simbólica Andina. La Paz, CIPCA, 1976.

Tschopik, Harry. The Aymara of Chucuito, Perú. Nueva York, Anthropological Papers of the American Museum of Natural History, 1951, Vol. I. Parte 2.

Urton, Gary. At the Crossroads of the Earth and the Sky: An Andean Cosmology. Austin, University of Texas Press, 1981.

Vallée, Lionel. "El Discurso Mítico de Santa Cruz Pachacuti Yamqui". Allpanchis (Cusco, Perú) 1982, 20, pp. 103- 126.

Vansina, Jan. Oral Tradition. Chicago, Aldine, 1961.

Zuidema, R.T. y Gary Urton. "La Constelación de la Llama en Los Andes Peruanos". Allpanchis (Cusco, Perú), 1976, 9, pp. 59-119. 